\title{
The roles of catechins and caffeine in cream formation in a semi-fermented tea
}

\author{
Yu Chang Chao ${ }^{1}$ and Been Huang Chiang ${ }^{2 *}$ \\ ${ }^{1}$ Department of Food Nutrition, China Junior College of Medical Technology, Tainan, Taiwan \\ ${ }^{2}$ Graduate Institute of Food Science and Technology, National Taiwan University, Taipei, Taiwan
}

\begin{abstract}
The mechanism of cream formation in a semi-fermented tea was investigated by adding caffeine or catechins to the de-creamed tea infusions. The addition of catechins to the clarified infusion could not re-induce cream formation. However, creaming occurred again after replenishing the decreamed tea infusion with caffeine. It was thought that the ester-form catechins which possessed a galloyl group and a hydroxylphenyl $B$ ring acted like a claw. They could thus entrap and interact with caffeine more effectively through hydrogen bonding and hydrophobic interaction to form a large complex, resulting in creaming.

(C) 1999 Society of Chemical Industry
\end{abstract}

Keywords: tea cream; caffeine; catechins

\section{INTRODUCTION}

Creaming often occurs when a hot tea infusion is cooled to a lower temperature. The development of cloudiness in tea is generally considered undesirable because it presents an unattractive appearance and causes processing difficulties during concentration and heat treatment.

For black tea, a highly fermented tea product, the caffeine, theaflavins and thearubigins, which are produced from flavanols oxidized by polyphenol oxidase, are the major components of the cream. ${ }^{1,2}$ Other minor compounds, including biflavanols, unoxidized flavanols, pectin, caffeic acid, gallic acid, ellagic acid, proteins, humic acid-like substance, lipid complexes and minerals, are also found in black tea cream. ${ }^{1-5}$

The interactions among the cream compounds have not received much attention due to the variability of the composition of the cream. Some studies indicated that the extent of cream formation is affected by the concentration of caffeine in a black tea infusion. ${ }^{2,6,7}$ The amount of thearubigins was also suggested to be related to the degree of creaming. ${ }^{8}$ Hydrogen bonding is considered to be the most important interactive force among black-tea cream components. Other interactive forces, such as hydrophobic and ionic interactions, have also been reported to play a role.

Although polyphenols and caffeine are also major components of the cream of a semi-fermented tea, the effect of less-oxidized and less-polymerized phenolic compounds in semi-fermented tea on cream formation is not clear. Therefore, the objectives of this study were to explore the role of flavanols (catechins) and caffeine in cream formation, and the possible mechanisms of the creaming phenomenon in a semi-fermented tea.

\section{MATERIALS AND METHODS \\ Tea leaves}

All experiments were carried out with Paochung tea, obtained from the Tao Yuin area of north Taiwan. This semi-fermented tea was made from fresh tea leaves (TTES 12). The fresh leaves were solar withered for $c 20 \mathrm{~min}$ and then indoor withered for $c 8 \mathrm{~h}$. After panning at $270^{\circ} \mathrm{C}$ for $6 \mathrm{~min}$, the leaves were rolled for $c 7 \mathrm{~min}$ and dried at $95^{\circ} \mathrm{C}$ for $10 \mathrm{~min}$ in an oven (primary drying). The semi-dried leaves were subjected to ball-rolling and then final drying to a moisture content of $4 \%$. The tea leaves, stored in a freezer $\left(-10^{\circ} \mathrm{C}\right)$, were ground and screened through a 140-mesh sieve to remove the fine particles before extraction.

\section{Tea infusion and tea-cream determination}

Ground tea leaves were extracted with double-distilled water (tea leaf $/$ water $=5 \%, \mathrm{w} / \mathrm{w}$ ) at $90^{\circ} \mathrm{C}$ for $20 \mathrm{~min}$. The extracts were passed through a 140 -mesh sieve and then quickly cooled to $30^{\circ} \mathrm{C}$ or below using a glass condenser cooled with water $\left(25^{\circ} \mathrm{C}\right)$. They were then held in a waterbath at $2{ }^{\circ} \mathrm{C}$ for $2 \mathrm{~h}$ before centrifugation at $12500 \mathrm{~g}$ for $30 \mathrm{~min}$. The clarified supernatants were analysed for total solids contents. The amount of tea cream was estimated by calculating the difference

\footnotetext{
* Correspondence to: Been Huang Chiang, Graduate Institute of Food Science and Technology, National Taiwan University Taipei, Taiwan Contract/grant sponsor: Council of Agriculture, ROC; contract/grant number: 83-2.8-08(9)

(Received 19 March 1998; revised version received 24 September 1998; accepted 6 May 1999)
} 
between the total solids of the original and clarified infusions.

\section{Preparation of crude catechins}

Following the method of Matsuzaki and Hara, ${ }^{9}$ the tea infusion was decaffeinated by extracting twice with equal volumes of chloroform. The decaffeinated aqueous solution was partitioned three times against equal volumes of ethyl acetate. The ethyl acetate extracts were combined and dried in a rotary vacuum evaporator with gentle warming $\left(<40^{\circ} \mathrm{C}\right)$. The residue was re-suspended in a small volume of deionized water and then freeze-dried to form a crude catechins powder.

\section{Determination of the turbidity of tea infusion during cooling}

Tea infusion $(10 \mathrm{ml})$ was equilibrated at $40^{\circ} \mathrm{C}$ in a closed screw-topped tube $(20 \mathrm{ml})$. The turbidity of the tea infusion was monitored spectrophotometrically at $700 \mathrm{~nm}$ (Spectronic 3000 Array, Milton Roy Co, Rochester, NY, USA) when cooled from $40^{\circ} \mathrm{C}$ to $5^{\circ} \mathrm{C}$. The cooling rate was controlled at $c 0.5^{\circ} \mathrm{C} \mathrm{min}^{-1}$. During analysis, $1 \mathrm{ml}$ of the infusion was injected into a sample cuvette $(3 \mathrm{ml})$ at regular intervals. The temperature of sample cuvette holder was simultaneously controlled with cooling water pumped from the temperature programmed water bath (Model RC 20, Messgeraete-Werk Lauda Co, Lauda-Koenigshofen, Germany). The mean values for temperature and transmittance were simultaneously recorded to plot the turbidity curve during the cooling process.

\section{Analyses of polyphenols}

The tea infusions were diluted 20 times with deionized water, filtered through a $0.45 \mathrm{~mm}$ Millipore filter, and the filtrates analysed by HPLC. The chromatographic conditions were set according to the method of Terada et al: ${ }^{10}$ injection volume, $20 \mu \mathrm{l}$; column, Inersil 5 ODS80A (Vercoteck, Taipei, Taiwan), $250 \times 4.6 \mathrm{~mm}$; column temperature, $40^{\circ} \mathrm{C}$; mobile phase, Solvent A: $0.1 \%$ phosphoric acid containing $0.2 \%$ acetonitrile and $5 \% \mathrm{~N}, \mathrm{~N}$-dimethylformamide, Solvent B: acetonitrile; gradient: $99 \% \mathrm{~A}$ and $1 \% \mathrm{~B}$ to $30 \% \mathrm{~A}$ and $70 \% \mathrm{~B}$ over $60 \mathrm{~min}$; flow rate, $1 \mathrm{ml} \mathrm{min}^{-1}$; and UV detector at $280 \mathrm{~nm}$. The catechins kit contained $(+)$-catechin, (-)-epigallocatechin, (-)-epicatechin, (-)-epigallocatechin gallate, and (-)-epicatechin gallate and was purchased from Nuhunakoshi Co (Tokyo, Japan). Gallic acid, caffeine, rutin and quercetin were purchased from Sigma Co (St Louis, MO). These authentic compounds were used to identify peaks by co-chromatography.

All experiments were duplicated and three measurements were conducted for each test. The data were statistically analysed using analysis of variance with the SAS program for PC. ${ }^{11}$ Duncan's multiple range test was also applied to determine whether there were significant differences between individual treatments.

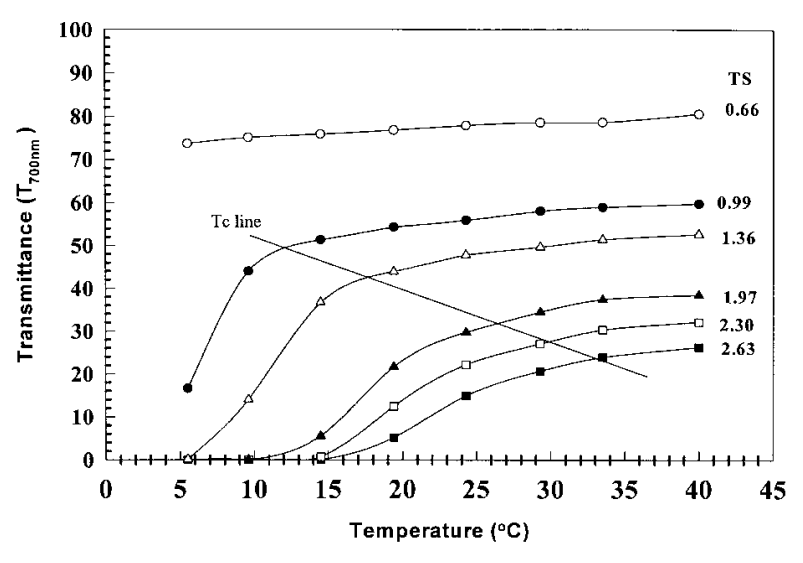

Figure 1. Changes of transmittance curves of the tea infusions with various total solids (in g per $100 \mathrm{ml}$ ) when cooled from $40^{\circ} \mathrm{C}$ to $5^{\circ} \mathrm{C}$ and the cooling rate controlled at $c 0.5^{\circ} \mathrm{C} \mathrm{min}{ }^{-1}$. Tc is the starting temperature of cream formation.

\section{RESULTS AND DISCUSSION}

\section{The phenomena of cream formation}

The amount of cream formed was highly dependent upon the total solids in the semi-fermented tea infusion. During cooling, the tea infusion presented a cloudy appearance before the precipitate formed. Thus, the transmittance of the infusion at $700 \mathrm{~nm}$ was used as a simple way to determine cream formation. The changes in transmittance of the tea infusions with various solid contents when cooled from 40 to $5^{\circ} \mathrm{C}$ are illustrated in Fig 1 . The temperatures at which the transmittance curves declined most drastically were considered to be the starting temperatures for cream formation $\left(T_{C}\right)$. Results showed that the higher the total solids in the infusion, the higher the $T_{C}$ observed. The transmittance of the tea infusion of $0.66 \%$ solids declined only slightly when the temperature dropped to as low as $5^{\circ} \mathrm{C}$, suggesting that the complexation of the tea components to form haze required a minimum concentration of total solids.

\section{Effects of caffeine and catechins on cream formation} Rutter and Stainby ${ }^{6}$ suggested that cream formation in black tea was primarily induced by the least-soluble complexes as a nucleus for the precipitation, and the nucleus resulted from the complexation of caffeine and highly oxidized polyphenols (eg theaflavins and thearubigins). However, the highly oxidized polyphenols produced by polyphenol oxidase were not present in the semi-fermented tea used in this study. Table 1 shows the concentrations of the major tea-cream components in the tea infusion before and after removing the tea cream by centrifugation. Notably, the concentrations of caffeine and catechins, the main components in the semi-fermented tea cream, remained at $c 80 \%$ and $90 \%$ of their original concentrations, respectively, after clarification. It was also found that the concentrations of caffeine and catechins of the clarified tea infusion which had a high original solids content were higher than those in the original infusion 
Table 1. The concentrations of caffeine and catechins in tea infusions before and after clarification

\begin{tabular}{|c|c|c|c|c|}
\hline \multirow[b]{2}{*}{$\begin{array}{l}\text { Total solids }{ }^{1} \\
\text { (g per } 100 \mathrm{ml} \text { ) }\end{array}$} & \multicolumn{2}{|c|}{ Caffeine (g per $100 \mathrm{ml}$ ) } & \multicolumn{2}{|c|}{ Catechins (g per $100 \mathrm{ml}$ ) } \\
\hline & $\begin{array}{c}\text { Before } \\
\text { clarification }\end{array}$ & $\begin{array}{c}\text { After } \\
\text { clarification }\end{array}$ & $\begin{array}{c}\text { Before } \\
\text { clarification }\end{array}$ & $\begin{array}{c}\text { After } \\
\text { clarification }\end{array}$ \\
\hline $1.97( \pm 0.01)^{a}$ & $0.22( \pm 0.00)^{\mathrm{a}}$ & $0.17( \pm 0.00)^{a}$ & $0.76( \pm 0.01)^{a}$ & $0.72( \pm 0.00)^{a}$ \\
\hline $3.11( \pm 0.03)^{b}$ & $0.33( \pm 0.00)^{b}$ & $0.25( \pm 0.0)^{b}$ & $1.24( \pm 0.01)^{\mathrm{b}}$ & $1.11( \pm 0.02)^{b}$ \\
\hline $3.84( \pm 0.06)^{c}$ & $0.38( \pm 0.00)^{c}$ & $0.30( \pm 0.00)^{\mathrm{C}}$ & $1.50( \pm 0.01)^{\mathrm{c}}$ & $1.32( \pm 0.02)^{c}$ \\
\hline $4.69( \pm 0.06)^{d}$ & $0.50( \pm 0.00)^{d}$ & $0.34( \pm 0.01)^{d}$ & $1.79( \pm 0.01)^{d}$ & $1.54( \pm 0.00)^{d}$ \\
\hline $5.47( \pm 0.01)^{\mathrm{e}}$ & $0.58( \pm 0.00)^{\mathrm{e}}$ & $0.39( \pm 0.00)^{e}$ & $2.14( \pm 0.01)^{\mathrm{e}}$ & $1.76( \pm 0.00)^{\mathrm{e}}$ \\
\hline
\end{tabular}

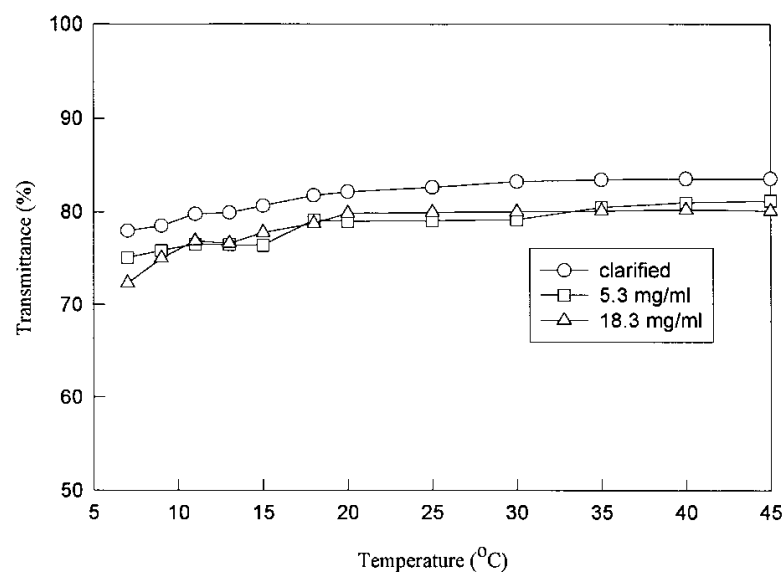

Figure 2. Effects of the addition of catechins $\left(5.3\right.$ and $18.3 \mathrm{mg} \mathrm{ml}^{-1}$, respectively) on the transmittance $(700 \mathrm{~nm})$ of the clarified infusions during cooling from $45^{\circ} \mathrm{C}$ to $5^{\circ} \mathrm{C}$. Total solids in the clarified infusion $1.69 \mathrm{~g}$ per $100 \mathrm{ml}$ and cooling rate controlled at $c 0.5^{\circ} \mathrm{C} \mathrm{min}^{-1}$.

with a low solids content. Therefore, it may be inferred that a deficiency of caffeine or catechins was not the major reason the insoluble complex did not form in the clarified infusion.

In order to explore the role of catechins in cream formation, amounts of catechins ranging from $5.3 \mathrm{mg} \mathrm{ml}^{-1}$ to $18.3 \mathrm{mg} \mathrm{ml}^{-1}$ were added to the clarified tea infusion. It was found that no significant creaming occurred during cooling (Fig 2). On the other hand, creaming occurred between 10 and $20^{\circ} \mathrm{C}$ when $6.2 \mathrm{mg} \mathrm{ml}^{-1}$ to $15.2 \mathrm{mg} \mathrm{ml}^{-1}$ of caffeine was added to the clarified infusion (Fig 3). The higher the amount of caffeine added, the higher the temperature for cream formation.

To investigate the types of polyphenolic compounds which were complexed with caffeine to produce cream, caffeine was added to the clarified infusion to induce further cream formation and then de-creamed again. Figure 4 shows the reduction of polyphenolic compounds in the infusion after such a second decreaming. The catechin esters, $(-)$-epicatechin gallate and (-)-epigallocatechin gallate, had a higher tendency to complex with caffeine than the non-ester forms, (-)-epicatechin, (+)-catechin and (-)-epigallocatechin.

Model solutions were used to confirm the roles of catechins in creaming. When crude catechins, which

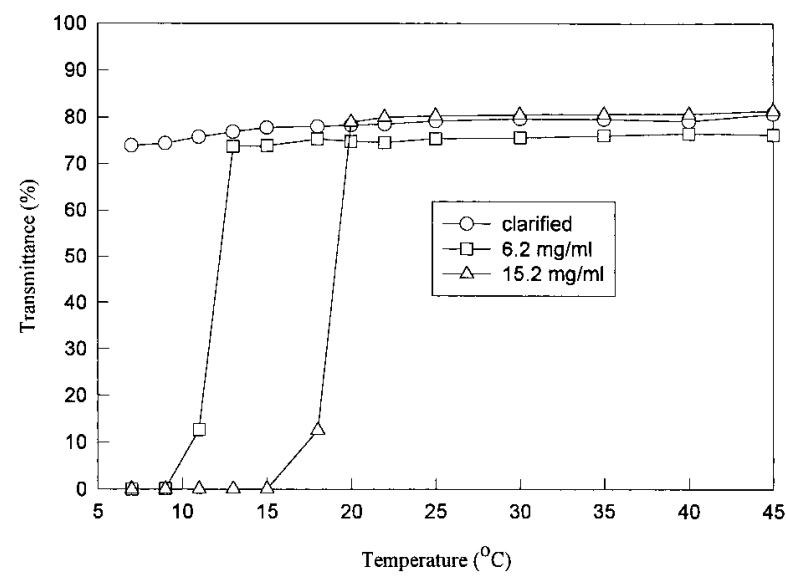

Figure 3. Effects of the addition of caffeine $\left(6.2\right.$ and $15.2 \mathrm{mg} \mathrm{ml}^{-1}$, respectively) on the transmittance $(700 \mathrm{~nm})$ of the clarified infusions during cooling from $45^{\circ} \mathrm{C}$ to $5^{\circ} \mathrm{C}$. Total solids in the clarified infusion $1.69 \mathrm{~g}$ per $100 \mathrm{ml}$ and cooling rate controlled at $c 0.5^{\circ} \mathrm{C}$ per min.

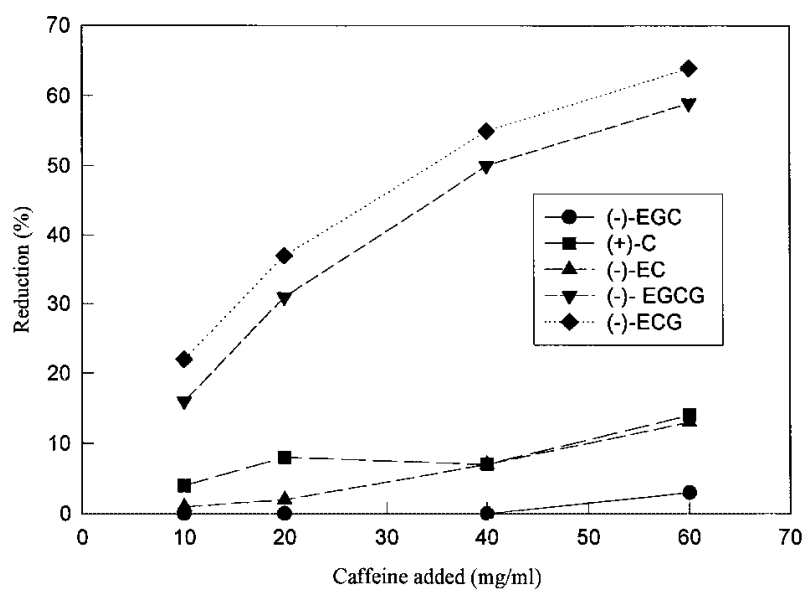

Figure 4. Reduction of polyphenolic compounds in a clarified infusion $(1.65 \mathrm{~g}$ per $100 \mathrm{ml})$ after addition of caffeine to re-induce cream formation and re-clarification.

contain a large amount of catechin esters, were mixed with caffeine, the mixture turned cloudy gradually during cooling, and the Tc of the caffeine-crude catechins mixture was $c 32^{\circ} \mathrm{C}$ (Fig 5). But when caffeine was mixed with (-)-epicatechin, a non-ester form compound, the Tc of the caffeine-(-)-epicatechin mixture and the pure $(-)$-epicatechin solution were essentially the same, approximately $6^{\circ} \mathrm{C}$. It 


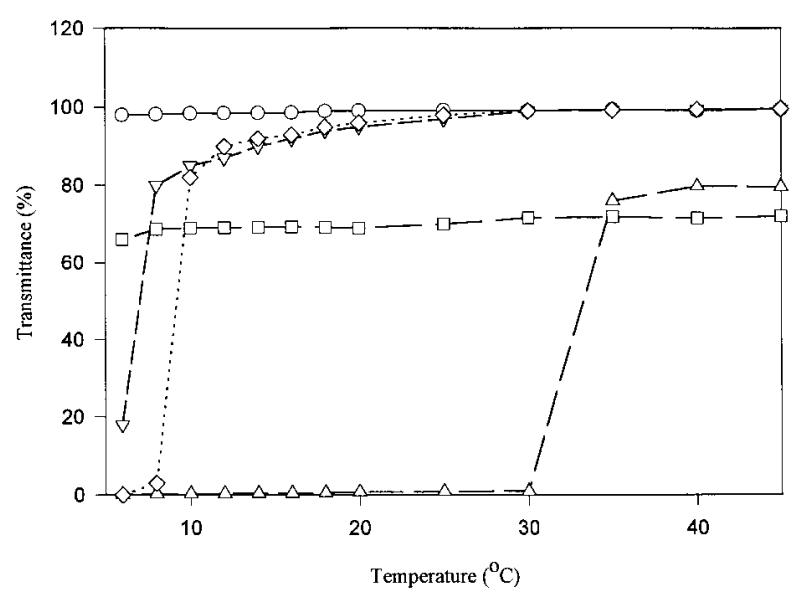

Figure 5. Changes of the transmittance $(700 \mathrm{~nm})$ of the model solutions of tea components during cooling. (O) $0.38 \mathrm{~g}$ per $100 \mathrm{ml}$ caffeine solution, $(\square) 1.50 \mathrm{~g}$ per $100 \mathrm{ml}$ crude catechins solution, $(\triangle) 0.38 \mathrm{~g}$ per $100 \mathrm{ml}$ caffeine and $1.50 \mathrm{~g}$ per $100 \mathrm{ml}$ crude catechins mixture, $(\nabla) 1.50 \mathrm{~g}$ per $100 \mathrm{ml}(-)$-epicatechin solution, $(\diamond) 0.38 \mathrm{~g}$ per $100 \mathrm{ml}$ caffeine and $1.50 \mathrm{~g}$ per $100 \mathrm{ml}$ caffeine and $(-)$-epicatechin mixture.

was suspected that the development of cloudiness at a lower temperature in the caffeine- $(-)$-epicatechin mixture and the (-)-epicatechin solution was the result of their limited solubilities at low temperature. These results further demonstrated that the complexation of caffeine and the ester form of catechins was responsible for cream formation in the semifermented tea.

\section{Complexation of caffeine and catechins}

Martin et $a l^{12}$ studied the crystalline structure of a caffeine-methyl gallate complex using x-ray diffraction. They proposed that the complex formed through the six-membered rings of caffeine and methyl gallate eclipsed each other in a stacking arrangement with hydrophobic interaction, simultaneous intermolecular hydrogen bonding stabilizing this arrangement. Accordingly, it was believed that both hydrogen bonding and hydrophobic interaction are important in tea-cream formation. Considering the structure of catechins, the ester forms possess extra hydroxyl groups in the gallic acid ring. These hydroxyl groups provide additional intermolecular hydrogen-bonding sites for caffeine. In this respect, the ester-form catechins, possessing a galloyl group and the hydroxyphenyl B ring, could behave bifunctionally. Because of such a claw-like effect, the complex formed by the interaction of caffeine and the ester-form catechins would have a more compact structure than that formed with non-ester form catechins. In consequence, the ester-form catechins tend to form a larger, more compact, and less soluble complex with caffeine and thus play the key role in the creaming process of the semi-fermented tea.

\section{CONCLUSION}

Caffeine in the semi-fermented tea was the principal compound for inducing cream formation. The complexation between caffeine and the ester-form catechins through both hydrogen bonding and hydrophobic interaction played an important role in the creaming process, thought to be enhanced through a claw-like effect of the adjacent galloyl group and hydroxyphenyl B ring of the ester-form catechins.

\section{ACKNOWLEDGEMENTS}

This research was supported by the Council of Agriculture, ROC under the project number 83-2.8-08(9)

\section{REFERENCES}

1 Roberts EAH, The phenolic substances of manufactured tea. The creaming down of tea liquors. F Sci Food Agri 14:700-705 (1963).

2 Smith RF, Studies on the formation and composition of cream in tea infusion. I Sci Food Agri 19:530-534 (1968).

3 Nagalakshimi $S$ and Seshadri R, A study of nitrogenous constituents of tea cream. F Food Sci Technol 20:243-245 (1983).

4 Seshadri R and Nagalakshimi D, New hydrophobic lipid interaction in tea cream. I Sci Food Agri 45:79-86 (1988).

5 Powell C, Clifford MN, Opie SC, Ford MA, Robertson A and Gibson CL, Tea cream formation: The contribution of black tea phenolic pigments determined by HPLC. I Sci Food Agri 63:77-86 (1992).

6 Rutter P and Stainsby G, The solubility of tea cream. $\mathcal{F}$ Sci Food Agri 26:455-463 (1975).

7 Collier PD, Mallows R and Thomas PE, Interactions between theaflavins, flavanols and caffeine. Phytochem 11:867 (1972).

8 Hazarika M, Chakravarty SH and Mahanta PK, Studies on thearubigins pigments in black tea manufacturing systems. $\mathcal{F}$ Sci Food Agri 35:1208-1218 (1984).

9 Matsuzaki T and Hara Y, Antioxidative activity of tea leaf catechins. Nippon Nogeikagaku Kaishi 59:129-134 (1985).

10 Terada S, Maeda Y, Masui T, Suzuki, Y and Ina K, Comparison of caffeine and catechin components in infusion of various tea (Green, Oolong and Black tea) and tea drinks. Nippon Shikuhin Kogyo Gakkaishi 34:20-27 (1987).

11 SAS Institute, Inc, SAS User's Guide, Version 5, SAS Institute Inc, Cary, NC (1985).

12 Martin R, Lilley TH, Bailey NA, Falshaw CP, Haslam E, Magnolato D and Begley MJ, Polyphenols-caffeine complexation. 7 Chem Soc Chem Commun 105-106 (1986). 